\title{
Shell wiping in Calliostoma zizyphinum: the use of pedal mucus as a provendering agent and its contribution to daily energetic requirements
}

\author{
Sebastian P. Holmes*, Claire J. Sturgess, Andrew Cherrill, Mark S. Davies \\ The Northumbrian Water Ecology Centre, The Science Complex, The University of Sunderland, Sunderland \\ SR1 3SD, Tyne \& Wear, United Kingdom
}

\begin{abstract}
The phenomenon of shell wiping in Calliostoma zizyphinum (L.) was investigated with regard to its potential function as a feeding adaptation. It was determined that $C$. zizyphinum will, on average, wipe the surface of its shell with its foot twice every $24 \mathrm{~h}$, in the process consuming any matter that has adhered to the pedal mucus present on the surface of its shell. Examination of the importance of shell wiping to C. zizyphinum, both as a mechanism to reduce shell fouling and as a source of nutrition, revealed that the prevention of shell wiping resulted in a reduction in shell growth by a factor of 0.67 and an increase in shell fouling by a factor of 9. Measurement of the metabolic rate of C. zizyphinum ascertained that an average sized adult had a metabolic requirement of $\sim 117 \mathrm{~J}_{24} \mathrm{~h}^{-1}$. Examination of the ability of the pedal mucus produced by C. zizyphinum to act as a provendering agent showed that the pedal mucus produced by $C$. zizyphinum could increase the entrapment of particulate matter by a factor of 8 , and increase the chlorophyll a content of a substratum by a factor of 3. Calculation of the potential contribution of the matter trapped by pedal mucus, which is ingested through shell wiping, to the daily energetic requirements of C. zizyphinum revealed that shell wiping can contribute to approximately one-fifth of the daily energetic requirement of C. zizyphinum. Shell wiping therefore has an important role for both feeding and antifouling in C. zizyphinum.
\end{abstract}

KEY WORDS: Antifouling · Calliostoma zizyphinum · Energetics · Energy budgets · Pedal mucus · Provendering $\cdot$ Shell wiping

\section{INTRODUCTION}

The idea that marine prosobranch gastropods may use pedal mucus as a provendering agent is not novel. For example, incidences of marine mesogastropods (e.g. Hydrobia ulvae, Dendropoma corallinaceum, Littorina littorea) using pedal mucus to trap particulate matter from the water column and its subsequent consumption have been well documented (see Fenchel et al. 1976, Hughes 1978, Imrie 1992 respectively, and Barnes 1965, Purchon 1977, Kohn 1983, Barnes et al.

*Present address: Nederlands Instituut voor Onderzoek der Zee, Postbus 59, 1790 AB, Den Burg, Texel, The Netherlands.E-mail: holmes@nioz.nl
1988 for reviews). Given that the production of pedal mucus is an energetically expensive process, accounting for some 9 to $74 \%$ of the energy assimilated (see Davies \& Hawkins 1998 for review), the advantage to a mollusc in utilising pedal mucus as a provendering agent is evident. For the archaeogastropod molluscs of rocky shores, however, any evidence that they may use pedal mucus as a provendering agent has been circumstantial and/or indirect. That is, for pedal mucus to act as a provendering agent it must, by definition, both trap matter and be subsequently consumed. Although many authors have shown that the pedal mucus produced by archaeogastropods, particularly that of patellids, can trap particulate matter (see Connor \& Quinn 1984, Connor 1986, Davies et al. 1992, Santelices \& 
Bombadilla 1996), there is as yet no direct evidence that such molluscs will consume their pedal mucus once it has become organically enriched.

The archaeogastropod Calliostoma zizyphinum (L.) is a common inhabitant of the sublittoral fringe of many Northeastern Atlantic rocky shores, usually being found from the mean low-water neap mark down to 300 m (Fretter \& Graham 1977, Seaward 1982, Fish \& Fish 1996). In general very little is known about the ecology of $C$. zizyphinum other than some reproductive (Roberts 1902, Lebour 1936, 1938, Crofts 1955, Holmes 1997) and morphological (Seed 1979, Erwin \& Picton 1987, O'Loughlin \& Aldrich 1987a,b, Roberts \& Kell 1987, O'Loughlin 1989, Preston et al. 1993) details (see also Micallef 1967, Thompson et al. 1997). One aspect of the ecology of $C$. zizyphinum that has been recorded is that they will wipe the surface of their shell with their foot, leaving behind a coating of pedal mucus on the surface of their shell (Jones 1984; see Bryan et al. 1997 for details on shell wiping in $C$. canaliculatum). For C. zizyphinum, Jones (1984) suggested that such behaviour may serve to reduce shell fouling. In contrast, Bryan et al. (1997) demonstrated that for C. canaliculatum such behaviour can act as a mechanism to reduce predation pressure from opithuroids. Moreover, Theisen (1972) has shown that the bivalve Mytilus edulis will wipe the surface of its shell with its foot, in a manner similar to that of $C$. zizyphinum, and then consume any matter that has adhered to the pedal mucus, on the surface of its shell, at a later time. It is therefore possible that $C$. zizyphinum may be using the pedal mucus produced by itself and left on the surface of its shell as a provendering agent in a manner similar to that of M. edulis.

The aim of this study was to examine whether or not Calliostoma zizyphinum uses the pedal mucus produced by itself as a provendering agent, i.e. in combination with shell wiping, and if so to evaluate the importance of shell wiping to C. zizyphinum and estimate the potential contribution of the matter trapped by the pedal mucus to its daily energetic requirements.

\section{MATERIALS AND METHODS}

Collection sites and observations on the morphology of Calliostoma zizyphinum (L.). All experimental work was carried out over 2 years (1995 and 1996), using different populations in each year. The first population was sampled during November and December 1995 at Seal Sound, Clachan, Oban, Strathclyde, United Kingdom (National Grid Reference NM786198): Site 1; the second population was sampled from 15 to 30 May 1996 at Port Erin Breakwater, Port Erin, Isle of Man (National Grid Reference SC188691): Site 2. The ani- mals were collected at both sites by SCUBA diving within $10 \times 100 \mathrm{~m}$ zones, approximately $10 \mathrm{~m}$ below the water level at high tide. The substratum at Site 1 was composed of a rhyolite boulder bed heavily encrusted with Lithothamnion spp. and various sponges, and was fringed by mature Laminaria saccharina and Fucus vesiculosus. The substratum at Site 2 was composed of broken concrete blocks (maximum size $\sim 4 \times 4 \mathrm{~m}$ ) with an epiflora and epifauna very similar to that of Site 1.

The experiments using individuals from Site 1 were carried out at the Dove Marine Laboratory, Cullercoats, Newcastle upon Tyne, United Kingdom, and the experiments using individuals from Site 2 were carried out at Port Erin Marine Laboratory, Port Erin, Isle of Man. Once collected, the animals were transported to the laboratories in tanks of seawater (within $48 \mathrm{~h}$ in tanks of ice-cooled seawater for those collected from Site 1) and placed directly into tanks of running seawater $\left(\sim 10^{\circ} \mathrm{C}\right)$, subjected to natural illumination with a base substratum of algae-encrusted (Lithothamnion spp.) stones. Comparison of the shell heights (tip of spire to base of lip) and shell widths (widest body whorl) between sites, revealed that individuals from Site 1 were taller than those from Site 2 (Student's $t$ test, $t=8.23, \mathrm{p}=0.001 ; \mathrm{n}=397$ for Site $1, \mathrm{n}=523$ for Site 2). There were no differences in shell widths between populations $(t=0.265, \mathrm{p}=0.406)$. Mean \pm SE shell height of animals from Site 1 was $26.15 \pm$ $0.22 \mathrm{~mm}$, and $25.36 \pm 0.17 \mathrm{~mm}$ for those from Site 2; the overall mean \pm SE shell width was $20.39 \pm 0.20 \mathrm{~mm}$. The majority ( $90 \%)$ of animals at Site 1 were of the albino colour morph, whereas all individuals at Site 2 were of the pink variegated colour morph (see McMillan 1968 and Fretter \& Graham 1977 for descriptions).

Expt 1. (i) Observation of frequency and duration of shell wiping: All observations were made in autumn 1995 at the Dove Marine Laboratory. Examination of the frequency of shell wiping was made by placing a randomly selected individual into a clear glass tank, 30 $\times 30 \times 60 \mathrm{~cm}$ (length $\times$ width $\times$ height), which had been filled with running seawater $\left(\sim 10^{\circ} \mathrm{C}\right)$. The behaviour of the animal was then recorded on videotape over $24 \mathrm{~h}$, using a Panasonic F10 video camera attached to a time-lapse video recorder (lapse time $=6 \mathrm{~s}$ ). The video recording of the behaviour of each individual was then displayed on a television monitor, and analysed by recording the frequency and duration of the shell wiping incidents that occurred during the experimental period. (For a full description of the shell wiping behaviour exhibited by Calliostoma zizyphinum, see Jones 1984.) This whole procedure was repeated with a further 29 different animals, each on consecutive days (i.e. $\mathrm{n}=30$ in total).

(ii) Examination of consumption of matter adhering to shell surface: All investigations were made in 
autumn 1995 at the Dove Marine Laboratory and repeated in spring 1996 at the Port Erin Marine Laboratory. For both experiments, a modification of the procedure of Theisen (1972) was utilised. For the experiment carried out at the Dove Marine Laboratory, 60 animals were randomly selected, and the surface of their shells was cleaned by scrubbing with a nylon toothbrush until all the visibly adhered matter had been removed. The animals were then rinsed in ultraviolet-irradiated, filtered $(0.2 \mu \mathrm{m})$ seawater (UVFS) and their shells dried using an absorbent towel. After cleaning, all animals were placed together into a tank $(1 \times 1 \times 0.5 \mathrm{~m}$, length $\times$ width $\times$ height $)$ of aerated UVFS $\left(\sim 10^{\circ} \mathrm{C}\right)$ and left for $24 \mathrm{~h}$, i.e. to give them an opportunity to wipe their shells. A staining suspension was then prepared as follows: to $5 \mathrm{ml}$ AristaR ethanol, $3 \mathrm{~g}$ Sudan III stain (Sigma-Aldrich Company Ltd, Poole, Dorset, United Kingdom) was added and stirred until it had dissolved; $100 \mathrm{~g}$ fresh baking yeast (Saccharomyces cerevisiae) was made up into a thick suspension by adding $5 \mathrm{ml}$ UVFS and shaking vigorously; $2 \mathrm{ml}$ of the Sudan III solution was then added to the yeast suspension and left for $1 \mathrm{~h}$ so that the yeast cells could absorb the stain.

After $24 \mathrm{~h}$, the animals were removed from the tank and gently shaken to remove any excess seawater. Thirty randomly chosen individuals, i.e. out of the 60 , were then carefully dipped, spire downwards, into the staining suspension, making sure that none of their soft-body parts came into contact with the suspension. This procedure was repeated a further 2 times, at $5 \mathrm{~min}$ intervals, to ensure that the shell surface was completely covered with the staining suspension. The other 30 individuals (control) were subjected to the same procedure, with the exception that they were dipped into UVFS instead of the staining suspension. All animals were then carefully placed into a tank, the bottom of which was made of $5 \mathrm{~mm}$ mesh size, plastic wire suspended $10 \mathrm{~cm}$ above the base of the tank. At hourly periods for the first $6 \mathrm{~h}$, and thereafter for every $12 \mathrm{~h}$, the mesh base of the tank was carefully inspected for evidence of any staining suspension that might have fallen or leached off the shell surface of the animals. When any staining suspension was apparent, it was carefully washed off with a fine jet of seawater, with minimum disturbance to the animals. The animals were left for $48 \mathrm{~h}$ under a $12 \mathrm{~h}$ day/12 h night cycle. At the end of the experimental period, they were removed from the tank, wiped clean, and their gut contents dissected under a stereo-microscope (100× magnification) to check for the presence of any stained yeast cells.

The second replicate experiment used identical experimental treatments and protocols, except that the animals used were from Site 2 and that the staining suspension used was made up as follows: to $20 \mathrm{ml}$ AristaR ethanol, $3 \mathrm{~g}$ aniline blue (BDH Chemicals Ltd, Poole,
United Kingdom) and $3 \mathrm{~g}$ crystal violet (BDH Chemicals Ltd, Poole, United Kingdom) stain was added; $20 \mathrm{~g}$ Artemia sp. cysts (Artemia systems, Baasrocle, Belgium) were then added to this thin suspension, and enough dried brewer's yeast (Lewis Laboratories, Surrey, United Kingdom) to form a thick suspension. This thick suspension was then painted, by hand, directly onto the shells of the animals. At the end of the experimental period, the presence of any staining suspension and/or stained Artemia sp. cysts was checked for within the dissected guts of the animals. The second replicate experiment used a different procedure than the first experiment to determine if Calliostoma zizyphinum could ingest larger particulate matter.

Expt 2. (i) Effects of prevention of shell wiping on shell-surface fouling: All investigations were carried out in autumn 1995 at the Dove Marine Laboratory. From the animals collected at Site 1, 15 randomly selected individuals were subjected to 1 of the following 2 treatments: (1) the shells were cleaned by scrubbing the shell surface with a nylon toothbrush and then rinsing in UVFS (control treatment); (2) the shells were prepared as in (1), and then a plastic disc $(0.5 \times 80 \mathrm{~mm}$, depth $\times$ diameter) with a central hole cut out $(15 \mathrm{~mm}$ diameter) was fixed over the shell at the base of the spire using hot melt glue (Fig. 1).

The shells of the control individuals were randomly marked with a few drops of the hot melt glue as a procedural control. All animals were then placed into a tank of running seawater $\left(10^{\circ} \mathrm{C}\right)$ and left for $7 \mathrm{~d}$ under a $12 \mathrm{~h}$ day/12 $\mathrm{h}$ night cycle. They were then removed from the tank, stored in a tank of ice-chilled UVFS, and examined within $2 \mathrm{~d}$ using the Wet Scanning Electron Microscope (WSEM) facility at the University of Manchester. Because WSEM can examine living wet specimens, the biofilms, which are usually absent or distorted in fixed specimens, are readily visible (Sutton et al. 1994). Measurement of the area fouled on the shell surfaces was made by storing images dig-

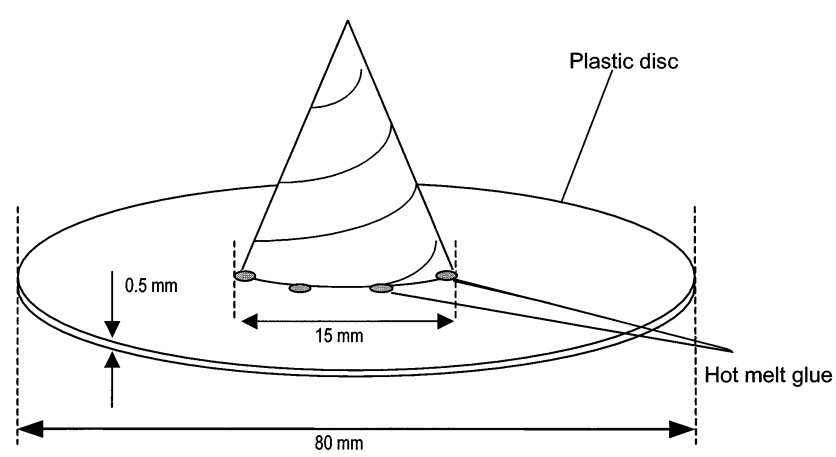

Fig. 1. Plastic disc glued onto the shell of Calliostoma zizyphinum to prevent shell wiping during the experiment 
itally obtained from the WSEM and analysing these images for the total area fouled. Three randomly selected areas $\left(12000 \mu^{2}\right)$ on each animal were selected for analysis using the National Institutes of Health image-analysis public-domain software (developed at the US National Institutes of Health and available on the Internet at http:/rsb.info.nih.gov/nihimage/) on a microcomputer.

(ii) Effects of prevention of the consumption of matter adhering to the shell surface on rate of shell growth: Investigations were carried out at Port Erin Marine Laboratory in spring 1996. Sixty Calliostoma zizyphinum, of $\sim 21 \mathrm{~mm}$ shell height, were selected at random and divided into 2 groups of 30 individuals each. The lip of the shell of all individuals was marked using a procedure modified from that of Ekaratne \& Crisp (1984), whereby a small indentation $(0.1 \mathrm{~mm}$ diameter) was drilled into the outside edge of the lip of a shell and marked with a non-toxic paint marker (Edding 751 paint marker, Edding, Germany). For 30 individuals the indentation was marked with an ' $\mathrm{x}$ ' (control), and for the remaining 30 individuals, the indentation was marked with an 'o' (treatment). Both groups were then placed into a tank of running seawater $\left(\sim 10^{\circ} \mathrm{C}\right)$, subjected to natural illumination. Treatment was as follows: at 09:00 and 21:00 h, both groups were removed from the tank. The shells of the treatment group were then individually cleaned by wiping each shell with an absorbent towel. Once all of the treatment animals had been cleaned, all animals were than placed back into the tank. This procedure was repeated consecutively for a further $27 \mathrm{~d}$. At the end of the experimental period, all animals were removed from the tank and their individual shell growth was measured as the distance ( $\mathrm{mm}$ ) from the lip of the shell to the centre of the indentation. In addition, the shell width and shell height of each animal were recorded.

Expt 3. Measurement of metabolic rate: Investigations were carried out in summer 1996 at Port Erin Marine Laboratory. The respiration rate of 30 randomly selected Calliostoma zizyphinum was measured using the closed-system manometric technique of Livingston (1968). Measurements of the oxygen consumed $\left(\mathrm{cm}^{3}\right)$ by an animal were taken after intervals of 1, 2, 3, 4, and $5 \mathrm{~h}$. The data for each individual were averaged to produce a reliable estimate of oxygen consumption $\mathrm{h}^{-1}$. For all measurements, the temperature was maintained at $10^{\circ} \mathrm{C}$ with a constant fluorescent illumination of $4.53 \mu \mathrm{E} \mathrm{m}^{-2} \mathrm{~s}^{-1}$. In addition, the shell height (from the tip of the spire to the base of the lip) and whole dry weight (shell cracked and dried at $40^{\circ} \mathrm{C}$ to constant dry weight) of each animal were measured. Conversion of the amount of oxygen consumed by an animal $\left(\mathrm{cm}^{3} \mathrm{~h}^{-1}\right)$ into metabolic rate $\left(\mathrm{J} \mathrm{h}^{-1}\right)$ can be made using the following equation of Schmidt-Nielsen (1997):

$$
M=O \times 20.11
$$

where $M=$ the metabolic rate $\left(\mathrm{J} \mathrm{h}^{-1}\right)$ and $O=\mathrm{O}_{2}$ consumed $\left(\mathrm{cm}^{3} \mathrm{~h}^{-1}\right)$.

Expt 4. Evaluation of provendering ability of the pedal mucus produced by Calliostoma zizyphinum and the associated calorific value of the microalgae trapped therein: All experiments were carried out in spring 1996 at Port Erin Marine Laboratory. Borosilicate ground-glass slides (Chance Propper Ltd, Warley, United Kingdom), $75 \times 25 \times 1 \mathrm{~mm}$, were used as a uniform substratum after autoclaving for $4 \mathrm{~h}$ at $1.2 \times 10^{5} \mathrm{~Pa}$ to ensure surface sterility (Prescott et al. 1993). Treatment (10 slides per treatment) was as follows: (1) the glass slides were placed on the bottom of a tank, which was filled with running filtered $(0.45 \mu \mathrm{m})$ seawater $\left(10^{\circ} \mathrm{C}\right)$ for $24 \mathrm{~h}$ as a control; (2) as in (1), except that 50 randomly selected Calliostoma zizyphinum were placed onto the submerged slides and allowed to crawl over them for $12 \mathrm{~h}$. The animals were prevented from crawling off the slides and up the sides of the tank by placing a $5 \times 5 \mathrm{~mm}$ mesh wire cage $10 \mathrm{~mm}$ above the height of the largest individual.

For both treatments, the temperature was maintained at $10^{\circ} \mathrm{C}$ and the tank was subjected to constant illumination from overhead fluorescent lights at $4.94 \mu \mathrm{E} \mathrm{m}^{-2} \mathrm{~s}^{-1}$. At the end of the preparation period, the slides were removed from the tanks and placed, in random order, into slide holders. The position of each slide within the slide holders was noted. The slide holders were then hung horizontally $10 \mathrm{~cm}$ below the surface of the seawater from a floating boom attached to Port Erin Pier (National Grid Reference SC192691) and left for $12 \mathrm{~h}$. After $12 \mathrm{~h}$, the slides holders were removed from the boom and the number of organisms (diatoms and algal propagules) that had adhered to each slide within 3 randomly selected areas $\left(0.02 \mathrm{~cm}^{2}\right.$, i.e. the area of the circular graticule used) on each slide was counted using a microscope.

To assess the calorific value of the algal material adhered to each slide, following counting, the chlorophyll a concentration of each slide was measured using the HMSO (1986) hot methanol-extraction procedure. Conversion of chlorophyll a $\left(\mu \mathrm{g} \mathrm{cm}^{-2}\right)$ to joules can be made using the following equations of Weast (1988) and Herburt (1990):

$$
C: C a=40: 1
$$

where $C=$ the number of carbon atoms, and $C a=$ the number of chlorophyll a molecules (Herburt 1990);

$$
\triangle C=394 \mathrm{~kJ} \mathrm{~mol}^{-1}
$$

where $\Delta C=$ the enthalpy of combustion of carbon (Weast 1988). 
It should be noted that conversion of chlorophyll a to available biomass in this fashion will give a very conservative estimate of the available biomass in terms of energetic value. This whole procedure was repeated a further 6 times on consecutive days using a fresh set of randomly selected Calliostoma zizyphinum (excluding those already used) from the original collection, i.e. 7 replicate experiments in all.

\section{RESULTS}

\section{Expt 1}

(i) Frequency of shell wiping

The mean \pm SE frequency of shell wiping in Calliostoma zizyphinum was $2.33 \pm 0.26$ incidents $24 \mathrm{~h}^{-1}$. The mean \pm SE duration of a shell wiping incident was $1076 \pm 175$ s (i.e. $17 \mathrm{~min}$ $56 \mathrm{~s} \pm 2 \min 55 \mathrm{~s})$. For the 30 animals examined, 27 wiped their shells at least once within the $24 \mathrm{~h}$ period, 23 wiped their shells 2 or more times in $24 \mathrm{~h}$, and 6 wiped their shells 5 or more times in $24 \mathrm{~h}$. All animals wiped their shells in an identical manner to that described by Jones (1984).

(ii) Consumption of matter adhering to shell surface

Of the 30 animals covered with the Sudan III yeast suspension, 27 con-
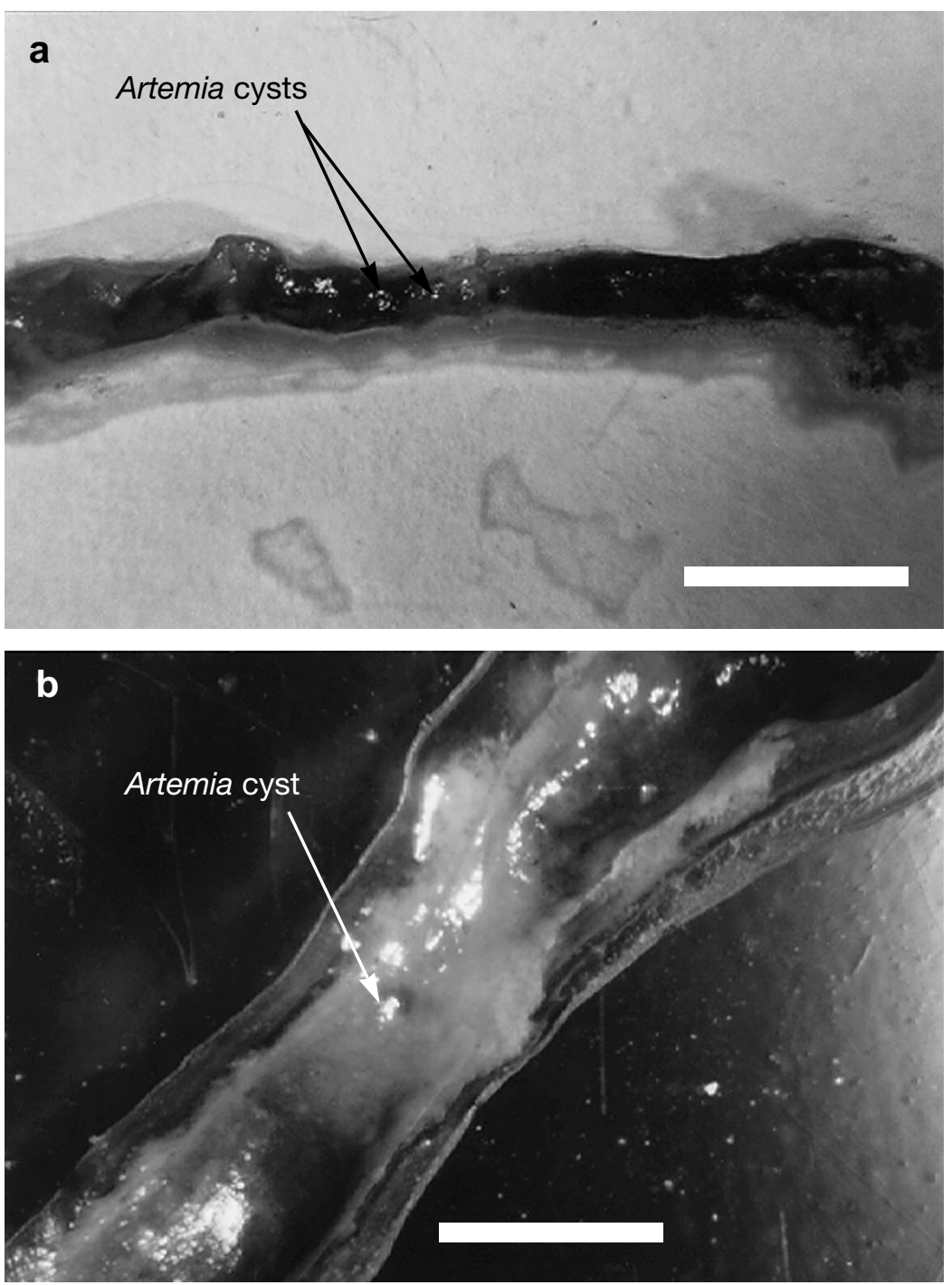

Fig. 2. Calliostoma zizyphinum. Gut contents, showing presence of Artemia sp. cysts within gut. Scale bars $=5 \mathrm{~mm}$ tained stained yeast cells within their guts. Of those covered with the aniline blue Artemia sp. cyst suspension, each animal was found to have either Artemia sp. cysts in its gut and/or stained epithelia (Fig. 2). In contrast to the results obtained for the treatment animals, examination of the guts of the 30 controls in the first experiment failed to reveal any presence of any stained yeast cells. For the 30 controls in the second replicate experiment, only 1 of the 30 animals showed any evidence of having ingested the staining suspension. Analysis of the data, for the sake of formality, using Fisher's 2-tailed exact comparison, determined for both experiments that the treated animals were ingesting the staining suspension $(p=0.001$ for both the first and second experiment), whereas the controls were not. In essence, Calliostoma zizyphinum

wipes the surface of its shell with its foot approximately twice every $24 \mathrm{~h}$ and, in doing so, consumes matter that has adhered to its shell since the last shell wiping incident.

\section{Expt 2}

\section{(i) Shell fouling}

Analysis of the WSEM results using a mixed model 2-level nested analysis of variance (ANOVA) revealed that the animals that had been prevented from wiping their shells were significantly more fouled (mean \pm SE: $0.87 \pm 0.02 \mathrm{~cm}^{2}$ fouled $\mathrm{cm}^{-2}$ ) than those that had been al- 
lowed to wipe their shells (mean $\pm \mathrm{SE}$ : $0.10 \pm 0.01 \mathrm{~cm}^{2}$ fouled $\mathrm{cm}^{-2}$ ) (Table 1 ) (Fig. 3). All other model terms were not statistically significant (Table 1). That is, the effects of the treatments on shell fouling are independent of any variation in the propensity of the animals to wipe their shells or of unknown factors. By preventing Calliostoma zizyphinum from wiping its shell, the fouling on its shell is increased by a factor of $\sim 9$.
Table 1. Calliostoma zizyphinum. Mixed model 2-level nested ANOVA of amount of shell fouling on animals that were allowed to wipe their shells and on animals that were prevented from wiping their shells. ${ }^{* * *}$ Significant at $\mathrm{p} \leq 0.001$

\begin{tabular}{|lrrrrr|}
\hline Source & df & \multicolumn{1}{c}{ SS } & MS & $F$ & \multicolumn{1}{c|}{ p } \\
\hline Treatment & 1 & 13.40 & 13.40 & 861.75 & $0.001^{* * *}$ \\
Animal & 28 & 0.44 & 0.016 & 1.40 & 0.140 \\
Residual & 60 & 0.67 & 0.011 & & \\
Total & 89 & & & & \\
& & & & & \\
\hline
\end{tabular}

\section{(ii) Shell growth}

Analysis of shell widths and shell heights of Calliostoma zizyphinum between treatment and control groups, using Student's $t$-tests, found no differences in either
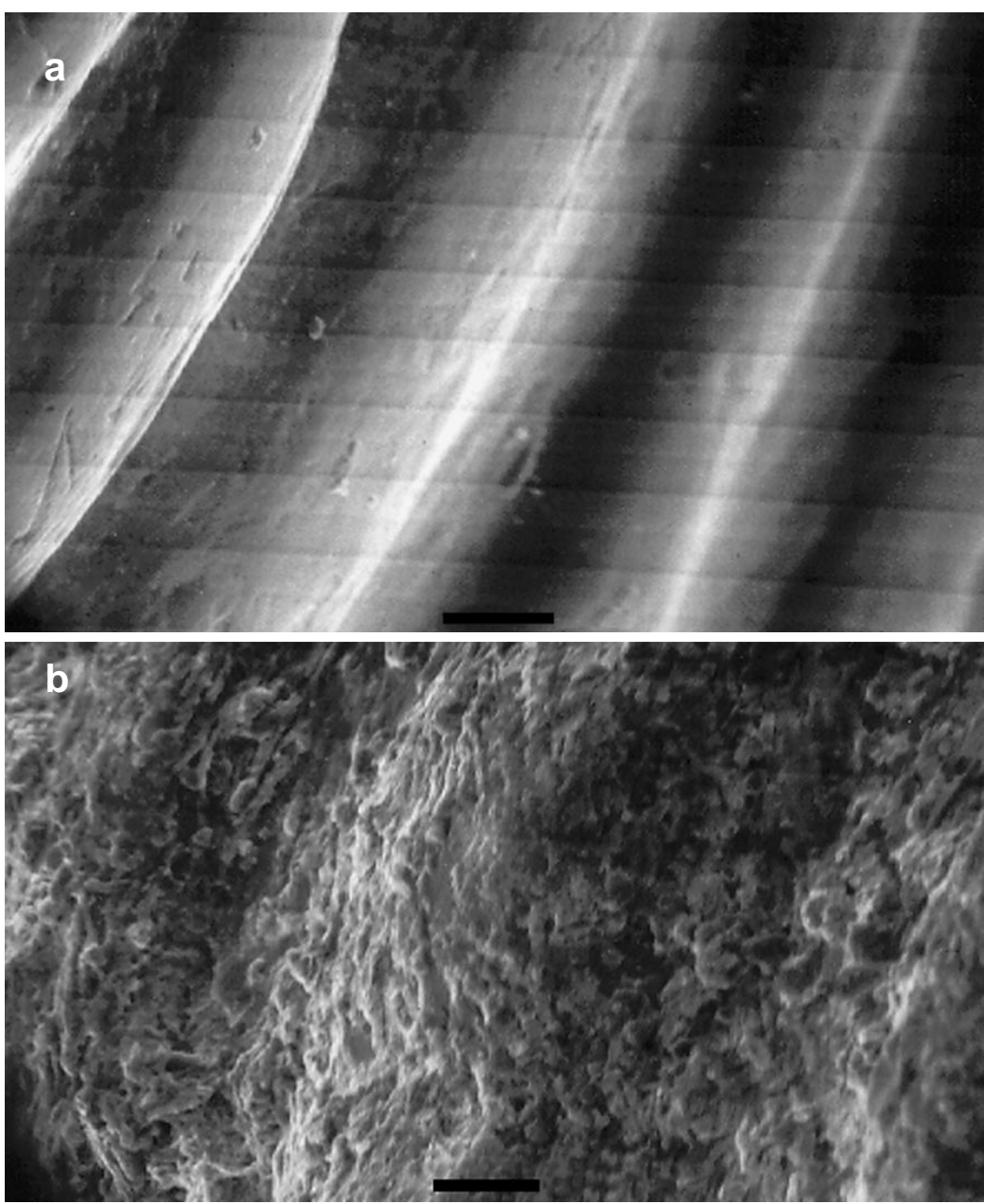

Fig. 3. Calliostoma zizyphinum. WSEM images of shell surface (a) of snail that was allowed to wipe its shell, and (b) of snail that was not allowed to wipe its shell. Scale bars $=50 \mu \mathrm{m}$ shell heights $(t=0.235, \mathrm{p}=0.816)$ and/or shell widths $(t=1.229, \mathrm{p}=0.229)$ between groups. Analysis of the data recorded for shell growth, using a $t$-test, determined that the growth of the shells of the controls (mean

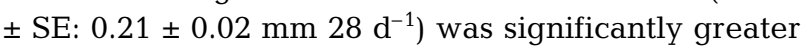
than the corresponding growth of the shells of the treated individuals (mean

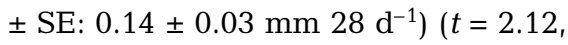
$\mathrm{p}=0.037$ ). By preventing C. zizyphinum from consuming epifauna adhering to its shell, its shell growth is decreased by a factor of 0.67 .

\section{Expt 3}

\section{Metabolic rate}

Linear regression of the $\log _{10}$-transformed data for the oxygen consumed by the animals $\left(\mathrm{cm}^{3} \mathrm{~h}^{-1}\right)$ against their whole dry weight and shell height (again $\log _{10}$-transformed) produced statistically significant relationships for both variables $(F=63.59, \mathrm{p}=0.001$, $\mathrm{r}^{2}=0.62$ for whole dry weight regressed against oxygen consumed and $F=29.04, \mathrm{p}=0.001$ and $\mathrm{r}^{2}=0.51$ for shell height regressed against oxygen consumed; Fig. 4). Using both the calculated regression equation for shell height (see Fig. 4), the equation of Schmidt-Nielsen (1997) (see 'Materials and methods') and assuming that an average sized individual is $25.36 \mathrm{~mm}$ in height (the mean height recorded for Calliostoma zizyphinum collected at Site 2), then the metabolic rate of that individual is equal to $4.89 \mathrm{~J}$ $\mathrm{h}^{-1}\left(1.17 \mathrm{cal} \mathrm{h}^{-1}\right)$. This is equivalent to a metabolic requirement of $117.41 \mathrm{~J}$ $24 \mathrm{~h}^{-1}$ (28.06 cal $\left.24 \mathrm{~h}^{-1}\right)$. 


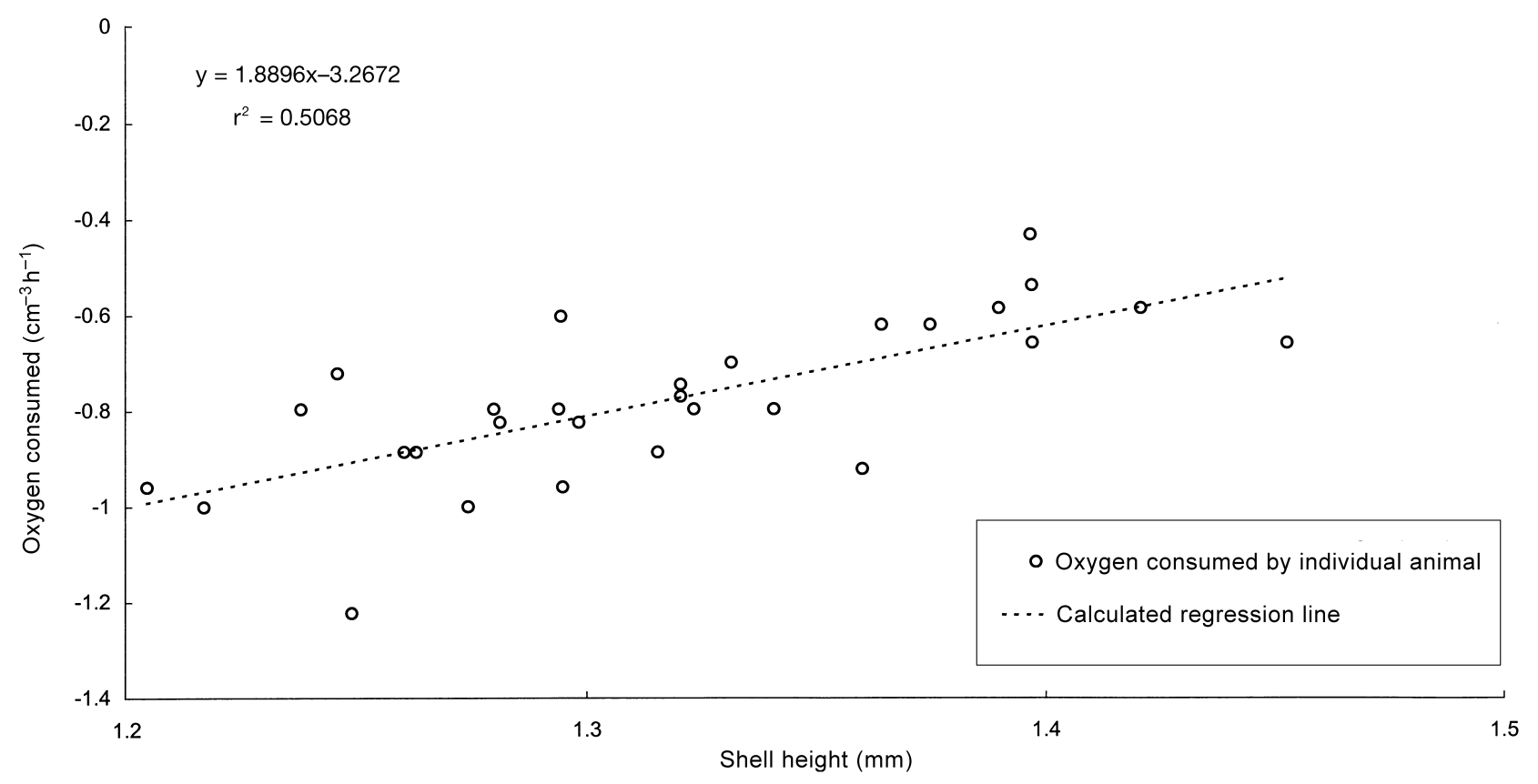

Fig. 4. Calliostoma zizyphinum. Oxygen consumed by each individual plotted against shell height (data $\log _{10}$-transformed)

\section{Expt 4}

Calorific value of matter trapped in pedal mucus

Analysis of the $\log _{10}$-transformed count data, using a mixed model 2-way ANOVA, revealed that the slides coated with the pedal mucus produced by Calliostoma zizyphinum entrapped significantly more organisms $\left(\right.$ mean \pm SE: $9264 \pm 1278$ organisms $\mathrm{cm}^{-2}$ ) than the control slides (mean \pm SE: $1201 \pm 268$ organisms cm$~^{-2}$ ) (Table 2). All other terms within the model were not statistically significant (Table 2). That is, the ability of the treatments to entrap microalgae is independent of any temporal variations in either microalgal recruitment and/or variations in the ability of the pedal mucus produced by $C$. zizyphinum to act as a provendering agent. The pedal mucus produced by C. zizyphinum can increase the number of microalgae adhering to its surface by a factor of $\sim 8$ compared to the control substratum.

Examination of the chlorophyll a content of the slides using a mixed model 2-way ANOVA, revealed, as for the count data, that the slides coated with the pedal mucus produced by Calliostoma zizyphinum had a significantly higher chlorophyll a concentration (mean \pm SE: $0.94 \pm 0.05 \mu \mathrm{g}$ chlorophyll $a \mathrm{~cm}^{-2}$ ) than the control slides (mean \pm SE: $0.32 \pm 0.02 \mu \mathrm{g}$ chlorophyll a cm${ }^{-2}$ ) (Table 3). All other model terms were not statistically significant (Table 3 ). The pedal mucus produced by $C$. zizyphinum can increase the chlorophyll a concentration of a substratum by a factor of $\sim 3$.

Using the carbon to chlorophyll a ratio of Herburt (1990) (see 'Materials and methods') the pedal mucus produced by Calliostoma zizyphinum entraps a mean energetic biomass of microalgae of $1.24 \mathrm{~J} \mathrm{~cm}^{-2} 12 \mathrm{~h}^{-1}$ $\left(0.294 \mathrm{cal} \mathrm{cm}^{-2} 12 \mathrm{~h}^{-1}\right)$. If it is assumed that the shell of C. zizyphinum is a perfect cone and that the height of an average-sized individual is $25.36 \mathrm{~mm}$, then the surface area of the shell of that individual can be calculated from $\pi \times$ the radius $\times$ the length of a shell, $=$ $8.80 \mathrm{~cm}^{2}$, and hence the energetic value of the available microalgal biomass that has adhered to the shell surface of that individual is equal to $10.91 \mathrm{~J}_{12} \mathrm{~h}^{-1}$ $\left(2.59\right.$ cal $\left.12 \mathrm{~h}^{-1}\right)$.

Table 2. Calliostoma zizyphinum. Mixed model 2-way ANOVA, $\log _{10}$-transformed data, of number of organisms adhering to control slides and to slides coated with pedal mucus. ${ }^{* *}$ Significant at $\mathrm{p} \leq 0.001$

\begin{tabular}{|lcrrrr|}
\hline Source & df & \multicolumn{1}{c}{ SS } & \multicolumn{1}{c|}{ MS } & \multicolumn{1}{c|}{$F$} & $\mathrm{p}$ \\
\hline Treatment & 1 & 81.30 & 81.30 & 3126.73 & $0.001^{* * *}$ \\
Replicates & 6 & 0.10 & 0.02 & 0.62 & 0.711 \\
Treatments $\times$ Replicates & 6 & 0.16 & 0.03 & 0.57 & 0.756 \\
Residual & 406 & 18.42 & 0.05 & & \\
Total & 419 & & & & \\
\hline
\end{tabular}


Table 3. Calliostoma zizyphinum. Mixed model 2-way ANOVA of chlorophyll a concentration on control slides and on slides coated with pedal mucus. ${ }^{* *}$ Significant at $\mathrm{p} \leq 0.001$

\begin{tabular}{|lrrrrr|}
\hline Source & df & SS & MS & $F$ & p \\
\hline Treatment & 1 & 13.06 & 13.06 & 563.17 & $0.001^{* * *}$ \\
Replicates & 6 & 0.43 & 0.07 & 3.06 & 0.100 \\
Treatments $\times$ Replicates & 6 & 0.14 & 0.02 & 0.21 & 0.974 \\
Residual & 126 & 14.20 & & & \\
Total & 139 & & & & \\
\hline
\end{tabular}

\section{DISCUSSION}

The first experiment in this paper revealed that Calliostoma zizyphinum will consume matter that has adhered to the pedal mucus remaining on the surface of its shell from a previous shell wiping incident. $C$. zizyphinum wipes its shell on average twice every $24 \mathrm{~h}$. The mean time recorded for a shell wiping incident (i.e. $1076 \pm 176 \mathrm{~s}$ ) is in line with those recorded by Jones (1984). The suggestion that the pedal mucus produced by archaeogastropods can act as a provendering agent (see Connor \& Quinn 1984, Connor 1986, Davies 1991, Davies et al. 1992), and hence potentially be of some nutritional benefit, is substantiated for $C$. zizyphinum at least. The presence of staining in the gut of one of the control animals in the first experiment probably resulted from the animal consuming stained matter either from the floor of the tank (i.e. matter which had fallen off one of the treated animals) or directly from the shell surface of one of the treatment animals.

The prevention of shell wiping in the second experiment resulted in both a reduction in the rate of shell growth of the treatment animals and a dramatic increase in their shell fouling. Haven (1973), Branch (1975) and Underwood (1976) have all shown that the shell growth of gastropods can be reduced in response to decreased availability of food (see Underwood 1979 and Branch 1981 for reviews). These results suggest that shell wiping is not only an important source of additional nutrition for Calliostoma zizyphinum but is also, as suggested by Jones (1984), an essential antifouling adaptation.

With regard to the potential contribution of the matter trapped in the pedal mucus on the shell surface of Calliostoma zizyphinum to the animal's daily energetic requirements, measurement of the metabolic rate determined that for an average-sized individual (i.e. $25.36 \mathrm{~mm}$ shell height) the metabolic rate would be

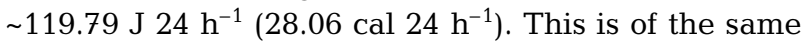
order of magnitude as values recorded in the literature for the metabolic rates of Nucella lapillus (Bayne \&
Scullard 1978), Littorina littorea (Sandeen et al. 1954, Newell \& Pye 1971) and Haliotis tuberculata (Peck et al. 1987) (see also Bayne \& Newell 1983 and Fretter \& Graham 1994 for reviews). It should be noted that the metabolic values obtained here represent a mean metabolic rate for individuals that were both active and stationary. Measurement of the provendering ability of the pedal mucus produced by $C$. zizyphinum revealed that it could increase the settlement of microalgae by $\sim 8$, equating to an energetic value of $1.24 \mathrm{~J} \mathrm{~cm}^{-2} 12 \mathrm{~h}^{-1}\left(0.294 \mathrm{cal} \mathrm{cm}^{-2} 12 \mathrm{~h}^{-1}\right)$. The values obtained for the effect of the pedal mucus produced by C. zizyphinum on the settlement of organisms (i.e. algae) are higher than those recorded by Connor \& Quinn (1984), Connor (1986), Davies et al. (1992), and Santelices \& Bombadilla (1996) for the effect of pedal mucus produced by other gastropod species over periods of 18, 24 and $12 \mathrm{~h}$, respectively (see also Holmes 1998). This would suggest that in contrast to the pedal mucus produced by other species, the pedal mucus produced by C. zizyphinum is an extremely effective provendering agent. The differences in the ability of the pedal mucus produced by different species to provender microalgae probably arise from differences in the chemical composition of the pedal mucuses, and hence in their adhesive potential and physio-chemical characteristics, etc. (see Connor 1986 and Holmes 1998 for discussions).

By combining the results of Expts 1 to 4, an estimation of the contribution of the microalgae, trapped in the pedal mucus produced by Calliostoma zizyphinum and consumed through shell wiping, to the animal's daily metabolic requirements can be made as follows: (1) during a $24 \mathrm{~h}$ period an individual, on average, wipes the surface of its shell twice, thereby consuming any matter which has adhered to its shell; (2) the calorific value of the matter adhering to its shell, assuming that the shell is a cone and perfectly smooth, is $10.91 \mathrm{~J}(2.59 \mathrm{cal})$ per shell wiping incident; (3) if the metabolic rate of an average-sized C. zizyphinum

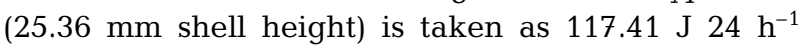
(28.06 cal $24 \mathrm{~h}^{-1}$ ), then the nutrition gained by an animal from the consumption of microalgae obtained through shell wiping contributes approximately onefifth of the daily energetic requirement of that animal, i.e. $10.91 \mathrm{~J}(2.59 \mathrm{cal})$ per shell wiping incident $\times 2$ inci-

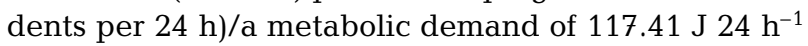
(28.06 cal $24 \mathrm{~h}^{-1}$ ).

This value is a 'ball-park' figure and should not be taken too literally. Although the calorific value of the microalgae adhered to the shell of the animals was 
consistently underestimated, it is possible that the 'real' energetic value of the matter adhering to the shell of $C$. zizyphinum is much higher; i.e. (1) it was assumed that the shell was a perfectly smooth cone, whereas in reality the surface area of the shell will be much greater due to its rugosity; (2) no account was taken of the potential contribution of either the pedal mucus and/or any non-algal matter that had adhered to the pedal mucus to the energetic value of the matter consumed; (3) the conversion of the carbon content of the microalgae to joules (energy units) would be much higher if simple organic compounds (carbohydrates) were considered, instead of using a direct carbon to energy conversion factor.

It should be remembered that the formula used to convert chlorophyll a to carbon (see Expt 4) has many associated errors (see Herburt 1990 for discussion) and that the energetic value of the microalgae adhering to the shell cannot be directly equated to assimilated energy. A significant improvement to the experimental design would be to clean the shells of the animals, in the field, using an oxidising agent, and then to observe them in situ with a video camera, wait until an animal has wiped its shell once, and then retrieve this animal when it begins to wipe its shell a second time. If the matter adhering to the shell were removed by brushing the shell in sterile seawater, then the resulting solution could be analysed for its adenosine triphosphate (ATP) content (see Holm-Hansen \& Booth 1966 and Herburt 1990), and hence a much more accurate measurement of the energetic value of the matter adhering to the shell surface can be made.

Conversely, it should be remembered that the calorific value of matter adhering to the pedal mucus present on the shell surface of Calliostoma zizyphinum measured under ideal conditions could be much less than that assimilated by the organism. For example, there would differences in the calorific value of matter adhering to a shell between seasons, the efficiency of transfer of matter from the shell to the mouth is unknown, and the difference between the calorific value of the matter consumed by an organism to that assimilated by an organism is not accounted for.

The importance of shell wiping to Calliostoma zizyphinum as a feeding adaptation is evident, i.e. the pedal mucus on the surface of the shells of the animal acts as a provendering agent to recoup some of the energy expended in the production of pedal mucus. If the energetic value of the matter consumed by C. zizyphinum is assumed to be equal to the assimilated energy from that matter, then shell wiping could provide more energy than is required for the production of pedal mucus (i.e. if the lowest estimate of $9 \%$ of assimilated energy [Kofed 1975] is taken as the cost for $C$. zizyphinum to produce pedal mucus). In contrast, if the cost of pedal mucus production is as high as $74 \%$ of the assimilated energy (Horn 1986), the consumption of matter adhering to the shell through shell wiping will provide at least a quarter of the energy required to produce pedal mucus. Unfortunately, because very little is known about the physiology of $C$. zizyphinum, the potential contribution of shell wiping to the overall energy budget of the animal cannot be calculated. Similarly, there are no observations in the literature as to the main source of nutrition for C. zizyphinum, although Perron (1975), Perron \& Turner (1978) and Ferro \& Cretella (1993) have shown that C. annulatum, C. variegatum, C. ligatum, C. granulatum and C. occidentale will feed on coelenterates (see also Clench \& Turner 1960, Keen 1975, Perron 1975, Quinn 1981).

It is worth noting that O'Loughlin \& Aldrich (1987b) have shown that the apical angle of Calliostoma zizyphinum living in fast-flowing water is greater than the corresponding angle of $C$. zizyphinum living in slow-flowing water. This suggests that the growth rate of C. zizyphinum in fast-flowing water is greater than that of $C$. zizyphinum living in slow-flowing water. Correspondingly, Erwin \& Picton (1987) have suggested that $C$. zizyphinum tends to be abundant only in regions of high water movement (see also Seed 1979, O'Loughlin \& Aldrich 1987a,b, O'Loughlin 1989 and Preston et al. 1993). Both of the populations sampled here are regularly exposed to water movement in excess of $2.5 \mathrm{~m} \mathrm{~s}^{-1}$, with the population at Site 1 experiencing greater water currents than the population at Site 2 (S.P.H. pers obs.). The Site 1 animals had a greater apical angle than those at Site 2 (i.e. the shell widths of both populations were the same but Site 1 individuals were taller than those at Site 2 [see 'Materials and methods']). If the apical angle of the shell is genuinely related to water current, and hence growth rate, then the growth rates of the animals will be determined, in part, by their daily nutritional intake. Individuals living in fast-flowing waters will therefore gain a greater nutritional intake, through shell wiping, than individuals living in slower-flowing waters. That is, as the water flow within an environment increases, so should the number of organisms contacting the shell of C. zizyphinum increase by virtue of the number of collisions likely to occur per unit time, and hence the nutritional value of the matter adhered to its shell should also increase. If so, and in view of the findings of O'Loughlin \& Aldrich (1987b) and the results reported here, the consumption of matter adhering to the shell surface of $C$. zizyphinum may make a major contribution to the animal's energetic requirements. Similar relationships between shell morphology and daily nutritional intake have been observed by Richardson et al. $(1980,1981)$ for the common cockle Cerastoderma edule (see also Jensen 1993, Kamermans 1993 
and Arnold et al. 1998). Notwithstanding, until a measurement of the energetic cost of pedal mucus production by C. zizyphinum, an accurate measurement of the total energy which can be assimilated from the matter adhering to the shell of $C$. zizyphinum, and observations on other sources of nutrition utilised by $C$. zizyphinum are made, this proposal is little more than speculation.

From an evolutionary standpoint, the consumption of pedal mucus which has acted as provendering agent would appear to be a sensible strategy for an organism that produces an exudate that is energetically costly to produce. The evolution of such a strategy in an organism is illustrated here by the phenomenon of shell wiping in Calliostoma zizyphinum, which appears to serve 2 important biological functions: to acquire nutrition and to prevent shell fouling.

Acknowledgements. We would like to thank Professors T. Norton and N. Owens for the generous use of their facilities at Port Erin Marine Laboratory and the Dove Marine Laboratory, respectively. Special thanks to Mr M. Bates for kindly obtaining numerous specimens for us during our stay at Port Erin, to $\mathrm{Mr} \mathrm{M}$. Duke for acting as a dive buddy at Oban, and to Miss N. Miller. In addition, we are indebted to Drs G. Walker and N. Clarkson for their willingness to review the proofs, and to Professor R. Seed for his advice and comments. Finally, we would like to note that the research published here was done whilst the principal investigator (S.P.H.) was carrying out research for a successful $\mathrm{PhD}$ thesis funded by the Ecology Centre at the University of Sunderland.

\section{LITERATURE CITED}

Arnold WS, Bert TM, Quitmyer IR, Jones DS (1998) Contemporaneous deposition of annual growth bands in Mercenaria mercenarai (Linnaeus), Mercenaria campechiensis (Gemlin), and their natural hybrid forms. J Exp Mar Biol Ecol 223:93-109

Barnes RD (1965) Invertebrate zoology. WB Saunders, Philadelphia

Barnes RSK, Calow P, Olive PJW (1988) The invertebrates: a new synthesis. Blackwell Scientific Publications, Oxford

Bayne BL, Newell RC (1983) Physiological energetics of marine molluscs. In: Saleuddin ASM, Wilbur KM (eds) The Mollusca - Physiology. Part 1. Vol 4. Academic Press, New York, p 407-515

Bayne BL, Scullard C (1978) Rates of oxygen consumption by Thais (Nucella) lapillus (L.). J Exp Mar Biol 32:97-111

Branch GM (1975) Intraspecific competition in Patella cochlear Born. J Anim Ecol 44:263-282

Branch GM (1981) The biology of limpets: physical factors, energy flow, and ecological interactions. Annu Rev Oceanogr Mar Biol 19:235-379

Bryan PJ, McClintock JB, Hamann M (1997) Behavioural and chemical defences of marine prosobranch gastropod Calliostoma canaliculatum in response to sympatric seastars. J Chem Ecol 23:645-658

Clench WJ, Turner RD (1960) The genus Calliostoma in the Western Atlantic. Johnsonia 4:1-80

Connor VM (1986) The use of mucous trails by intertidal limpets to enhance food resources. Biol Bull 171:548-564 Connor VM, Quinn JF (1984) Stimulation of food species growth by limpet mucus. Science 255:843-844

Crofts DR (1955) Muscle morphogenesis in primitive gastropods and its relation to torsion. Proc Zool Soc Lond 125: 711-750

Davies MS (1991) Studies on mucus from intertidal gastropods with reference to energy budgets. Phd thesis, University of Manchester

Davies MS, Hawkins SJ (1998) Mucus from marine molluscs. Adv Mar Biol 34:1-71

Davies MS, Hawkins SJ, Jones HD (1992) Pedal mucus and its influence on the microbial food-supply of two intertidal gastropods, Patella vulgata L and Littorina littorea (L). J Exp Mar Biol Ecol 161:57-77

Ekaratne SUK, Crisp DJ (1984) Seasonal growth-studies of intertidal gastropods from shell micro-growth band measurements, including a comparison with alternative methods. J Mar Biol Assoc UK 64:183-210

Erwin D, Picton B (1987) Guide to inshore marine life. The Marine Conservation Society, Immel, London

Fenchel T, Kofed LH, Lappalainen A (1976) Particle-size selection of two deposit feeders: the amphipod Corophium volutator and the prosobranch Hydrobia ulvae. Mar Biol 30:119-128

Ferro R, Cretella M (1993) Observations on the biology of Calliostoma granulatum (Born) (Gastropoda: Trochidae). Boll Malac 29:49-56

Fish JD, Fish S (1996) A student's guide to the seashore, 2nd edn. Cambridge University Press, Cambridge

Fretter V, Graham A (1977) The prosobranch molluscs of Britain and Denmark. Part 2-Trochacea. J Mollusc Stud (Suppl) 3:39-100

Fretter V, Graham A (1994) British prosobranch molluscs, 2nd edn. Ray Society, London

Haven SB (1973) Competition for food between two intertidal gastropods Acmaea scabra and Acmaea digitalis. Ecology 54:143-151

Herburt RA (1990) Methods for enumerating microorganisms and determining biomass in natural environments. In: Grigorova R, Norris JR (eds) Methods in microbiologytechniques in microbial ecology, Vol 22. Academic Press, London, p 1-40

HMSO (1986) The determination of chlorophyll $a$ in aquatic environments. In: Methods for the examination of water and associated materials, Vol 4. Her Majesty's Stationery Office, London, p 51-109

Holmes SP (1997) Notes on the gamete release and fertilization in Calliostoma zizyphinum (L.) (Gastropoda: Trochidae). J Mollusc Stud 63:471-473

Holmes SP (1998) The interaction between settling organisms and molluscs in the rocky intertidal. PhD thesis, University of Sunderland

Holm-Hansen O, Booth CR (1966) The measurement of adenosine triphosphate in the ocean and its ecological significance. Limnol Oceanogr 11:510-519

Horn PL (1986) Energetics of Chiton pelliserpentis (Quoy \& Gaimard 1835) (Mollusca: Polyplacophora) and the importance of mucus in its energy budget. J Exp Mar Biol Ecol 101:119-141

Hughes RN (1978) The biology of Dendropoma coralliaceum and Serpulobis natalensis, two South African vermetid gastropods. Zool J Linn Soc 64:111-127

Imrie DW (1992) The role of pedal mucus in the feeding behaviour of Littorina littorea (L.). In: Grahame J, Mill PJ, Reid DG (eds) Proc 3rd Symp on Littorinid Biology. The Malacological Society, London, p 221-226 
Jensen KT (1993) Density-dependent growth in cockles (Cerastoderma edule) - evidence from interannual comparisons. J Mar Biol Assoc UK 73:333-342

Jones HD (1984) Shell cleaning behaviour of Calliostoma zizyphinum. J Mollusc Stud 50:245-247

Kamermans P (1993) Food limitation in cockles (Cerastoderma edule (L.)) - influences of location on tidal flat and of the nearby presence of mussel beds. Neth J Sea Res 31: 71-81

Keen AM (1975) On some western American species of Calliostoma. Veliger 17:134-141

Kofed LH (1975) The feeding biology of Hydrobia ventrosa (Montagu). I. the assimilation of different components of food. J Exp Mar Biol Ecol 19:223-241

Kohn AJ (1983) Feeding biology in gastropods. In: Saleuddin ASM, Wilbur KM (eds) The Mollusca physiology. Part 2. Vol 5. Academic Press, New York, p 2-64

Lebour MV (1936) Notes on the eggs and larvae of some Plymouth prosobranchs. J Mar Biol Assoc UK 20:547-567

Lebour MV (1938) The eggs and larvae of the British prosobranchs with special reference to those living in the plankton. J Mar Biol Assoc UK 22:105-166

Livingston RJ (1968) A volumetric respirometer for long-term studies of small aquatic animals. J Mar Biol Assoc UK 48: 485-497

McMillan NF (1968) British shells. Warne, London

Micallef $H$ (1967) Aerial and aquatic respiration of certain trochids. Experimenta 23:52

Newell RC, Pye VI (1971) Variations in the relationship between oxygen consumption, body size and summated tissue metabolism in the winkle Littorina littorea. J Mar Biol Assoc UK 51:315-338

O'Loughlin EFM (1989) Notes on the distribution of Calliostoma zizyphinum (L.) (Mollusca) on the shores and shallow waters of the Irish coast. Bull Ir Biogeogr Soc 12: 22-30

O'Loughlin EFM, Aldrich JC (1987a) An analysis of shell shape variation in the painted topshell Calliostoma zizyphinum (L.) (Prosobranchia: Trochidae). J Mollusc Stud 53:62-68

O'Loughlin EFM, Aldrich JC (1987b) Morphological variation in the painted topshell Calliostoma zizyphinum (L.) (Prosobranchia: Trochidae) from inter-tidal rapids on the Irish coast. J Mollusc Stud 53:267-272

Peck LS, Culley MB, Helm MA (1987) A laboratory energy budget for the ormer Haliotis tuberculata L. J Exp Mar Biol Ecol 106:103-123

Perron FE (1975) Carnivorous Calliostoma (Prosobranchia: Trochidae) from the north-eastern Pacific. Veliger 18:52-54

Perron FE, Turner RD (1978) The feeding behaviour and diet of Calliostoma occidentale, a coelenterate-associated prosobranch gastropod. J Mollusc Stud 44:100-103

Prescott LM, Harley JP, Klein DA (1993) Microbiology, 2nd edn. Wm C Brown Publishers, Dubuque

Preston SJ, Roberts D, Montgomery WI (1993) Shell scarring

Editorial responsibility: Otto Kinne (Editor),

Oldendorf/Luhe, Germany in Calliostoma zizyphinum (Prosobranchia: Trochidae) from Strangford Lough, Northern Ireland. J Mollusc Stud 59:211-222

Purchon RD (1977) The biology of the Mollusca. Pergamon Press, Oxford

Quinn JF (1981) The gastropods, Calliostoma orion Dall 1989 (Trochidae) and Heliacus (Gyriscus) worsfoldi n. sp. (Architectonicidae), from the Bahama islands. Nautilus 95: 150-156

Richardson CA, Crisp DJ, Runham NW, Gruffydd LD (1980) The use of tidal growth bands in the shell of Cerastoderma edule to measure seasonal growth rates under cool temperatures and sub-arctic conditions. J Mar Biol Assoc UK 60:977-989

Richardson CA, Crisp DJ, Runham NW (1981) Factors influencing shell deposition during a tidal cycle in the intertidal bivalve Cerastoderma edule. J Mar Biol Assoc UK 61: 465-476

Roberts A (1902) Recherches sur le developpement des troques. Arch Zool Exp Gen 10:269-358

Roberts D, Kell GV (1987) Shell colour in Calliostoma zizyphinum (L.) from Strangford Lough, N Ireland. J Mollusc Stud 53:273-283

Sandeen MI, Stephens GC, Brown FA (1954) Persistent daily and tidal rhythms of oxygen consumption in two species of marine snails. Physiol Zool 27:350-356

Santelices B, Bombadilla M (1996) Gastropod pedal mucus retains seaweed propagules. J Exp Mar Biol Ecol 197: $251-261$

Schmidt-Nielsen K (1997) Animal physiology-adaptations and environment, 5th edn. Cambridge University Press, Cambridge

Seaward DR (1982) Sea area atlas of the marine molluscs of Britain and Ireland. Nature Conservancy Council/Conchological Society, Shrewsbury

Seed R (1979) Distribution and shell characteristics of painted topshell Calliostoma zizyphinum (L.) (Prosobranchia: Trochidae) in County Down, N Ireland. J Mollusc Stud 45: $12-18$

Sutton NA, Hughes N, Handley PS (1994) A comparison of conventional SEM techniques, low-temperature. J Appl Bact 76:448-458

Theisen BF (1972) Shell cleaning and deposit feeding in Mytilus edulis L. Ophelia 10:49-55

Thompson RC, Johnson LE, Hawkins SJ (1997) A method for spatial and temporal assessment of gastropod grazing intensity in the field: the use of radula scrapes on wax surfaces. J Exp Mar Biol Ecol 218:63-76

Underwood TM (1976) Food competition between age-classes in the intertidal neritacean Nerita atramentosa Reeve (Gastropoda: Prosobranchia). J Exp Mar Biol Ecol 23:145-154

Underwood TM (1979) The ecology of intertidal gastropods. Adv Mar Biol 16:111-210

Weast RC (1988) Handbook of chemistry and physics. CRC Press Inc, Boca Raton

Submitted: April 25, 2000; Accepted: July 27, 2000

Proofs received from author(s): February 7, 2001 